\title{
Evaluation of tonic immobility in common pheasant hens kept in different housing systems during laying period
}

\author{
Petra Hrabcakova, Iveta Bedanova, Eva Voslarova, Vladimira Pistekova and Vladimir Vecerek \\ Department of Veterinary Public Health and Toxicology, Faculty of Veterinary Hygiene and Ecology, University of \\ Veterinary and Pharmaceutical Sciences Brno, Czech Republic
}

\begin{abstract}
Common pheasant (Phasianus colchicus) hens kept in different housing systems during laying period were exposed to a tonic immobility test. At the end of the laying period, the shortest duration of the tonic immobility, and thus the lowest fear level, was found in birds kept in enriched cages, i.e. cages equipped with 2 perches and a hiding place. The duration of the tonic immobility in hens kept in enriched cages was significantly lower $(P<0.05)$ than in hens kept in conventional cages where other measures against feather pecking were used (beaktrimming and using spectacles, respectively).
\end{abstract}

Keywords: pheasant, tonic immobility, cage, enrichment, fear

\section{Introduction}

In Europe, the majority of driven pheasant shooting is supported by the release of captivereared pheasants to increase numbers of birds available to hunters (Draycott et al. 2002, 2005). Furthermore, increasing numbers of pheasants are raised commercially to be slaughtered for meat (Kuzniacka \& Adamski 2010, Kokoszynski et al. 2011). A substantial number of raised breeding pheasants in the breeding season is housed in cage systems (Zapletal et al. 2010). Keeling \& Gonyou (2001) have reported that the housing of domestic hens in conventional cages with higher stocking densities is associated with decreased egg production, higher mortality rate, more cases of feather pecking and cannibalism, and increased fearfulness. When pheasants are housed in conventional cage systems, the situation is similar in some respects. Such pheasants may show behavioural disorders that often result in various forms of aggression and cannibalism, seldom causing significant deterioration of health status or even death (Zapletal et al. 2010).

An appropriate environmental design is considered fundamental to ensure bird welfare (Campo \& Prieto 2009). Animal well-being can be improved by housing the animals in species-specific natural or near-to-natural environments. An enriched environment, e.g. the presence of perches may improve the welfare of chickens (Duncan et al. 1992, Pohle \& Cheng 2009). Enriched cages in laying hens have resulted in better bone quality, which may have been brought about from increased activity (Tactacan 2009). The issue of enriched cages and their influence on aggression levels, lower body weight and feather pecking has also been addressed by Jendral et al. (2005) and Pavlik et al. (2008). Olsson \& Keeling (2002) suggested that hens should be housed in systems with perches. The use of perches (Swan 1983) and 
lower stocking densities (Cain et al. 1984, Kjaer 2004) have been suggested as potential management prescriptions for reducing the levels of feather pecking also in pheasant pens.

Fehlberg et al. (1993) and Kjaer (1997) describe methods used in pheasants as prevention against injuring one another, particularly beak cauterisation or beak trimming when up to a third of the beak is removed and using various types of bits that are applied to the beak. Plastic or metal rings are clipped into the birds' nostrils to prevent the beak from closing. Some birds are forced to wear spectacles. Spectacles are used to reduce feather pecking, cannibalism and egg eating by pheasants in laying pens. These are plastic devices which are usually fitted onto the bird's beak and are designed to reduce feather pecking in pheasants by blocking their forward vision (Anonymous 2012). Spectacles can improve feather and skin condition in pheasants but they can cause damage to the bill and nostrils (Butler \& Davis 2010). Swarbrick (1985) suggested that bits might cause welfare issues, including increased mortality.

Evaluation of a pheasant rearing environment from the welfare viewpoint may be based on the fear level in birds. For evaluating the level of fear a tonic immobility test has become widely used (Jones \& Mills 1983, Mills \& Faure 1986). Tonic immobility (TI) is a fear-potentiated response induced by physical restraint (Jones \& Faure 1981) and is defined as generalised hypotonia caused by a short period of limitation of physical activity (Gallup 1977, Jones 1990). The TI test is based on a natural defensive reaction used by birds living in the wild when escaping a predator (anti-predator behaviour). The principle of this defence strategy is to remain completely motionless to dissuade the predator from attacking. The TI response is, therefore, an adaptive behavioural strategy. Its duration is considered to be positively related to the antecedent fear state, i.e. the more frightened the bird is when $\mathrm{Tl}$ is being induced, the longer it will remain immobile when released (Gallup 1979, Jones 1986b, Jones 1987, Jones 1992). The close associations found between TI reactions and estimated fear scores in a variety of tests support its use as an index of general underlying fearfulness and not just stimulus-specific fears (Jones \& Mills 1983, Jones 1987, Jones et al. 1991). The TI reaction is sensitive to a variety of social, genetic and environmental factors (Jones 1986a). Also relationships between $\mathrm{TI}$ and the habitat in which birds live have been studied (Bilčik et al. 1998, Hansen et al. 1993).

The aim of this study was to assess fear reactions of common pheasant hens housed during laying period in different housing systems.

\section{Material and methods}

\section{Birds and their treatment}

The TI test was performed on common pheasant (Phasianus colchicus) hens housed from the beginning of their laying period in a two-tiered cage battery. There was one breeding group consisting of 1 male and 5 hens in each cage. Each laying cage was equipped with a wirefloor, five automatic nipple drinkers and a trough feeder located before the cage's front wall with manual administration of feedings. The dimensions of the cage were as follows: $200 \mathrm{~cm}$ length, $85 \mathrm{~cm}$ depth, $58 \mathrm{~cm}$ back height and $70 \mathrm{~cm}$ front height. The floor had a slope towards the cage's front wall to enable the collection of laid eggs. The pheasants were fed with the pelleted feeding mixture BZN (ADW AGRO, a.s., Okríšky, Czech Republic). Lighting was only provided by daylight. 
When stocking the cages, the pheasants were split in the following housing systems:

Group 1: conventional cage (no perches, laying nests, claw-shortening devices or material for dust-bathing). Before being placed into a cage thermal cauterisation of one third of the upper part of the beak was performed on the pheasants.

Group 2: conventional cage (no perches, laying nests, claw-shortening devices or material for dust-bathing). Before being placed into a cage, as a protection against pecking one another, the pheasants were provided with commercially sold clip-on spectacles (Clip-On Specs, Agrigame, Great Britain) which did not harm the tissue and were applied on with pressure only.

Group 3: enriched cage (cage enriched with two perches and a place to hide created by strips of cloth hung in one corner of the cage, separating this corner from the rest of the cage). Neither cauterisation nor clip-on spectacles were used in this group.

\section{Tonic immobility tests}

A total of 45 pheasant hens ( 15 birds per test group) were used for testing for the duration of TI. At the end of the laying period 15 birds from each group were individually carried to a separate room and subjected to TI measurements according to a modified Benoff \& Siegel (1976) procedure. TI was induced by laying the bird down on its right side and gently restraining it by hand for $15 \mathrm{~s}$. The hand was then removed and the researcher retreated for approximately $1 \mathrm{~min}$ out of sight of the bird and remained silent. The time was measured from the removal of the hand until the bird straightened up. If the bird straightened up in less than $10 \mathrm{~s}$, it was restrained repeatedly. If TI was not induced after three attempts, the duration of TI was considered $0 \mathrm{~s}$. If the bird did not straighten up within $10 \mathrm{~min}$, it was removed and given the maximum duration of $600 \mathrm{~s}$. The number of inductions required to attain TI was also recorded for each bird.

\section{Statistical analysis}

The results were analysed using statistical software Unistat 5.1. (Unistat Ltd., London, UK). Before analysis, the data were checked for normality and homogeneity of variances (Shapiro-Wilk test and Bartlett-Box test), and because of their lack of fulfilment, data were then analysed by means of the non-parametric Kruscal-Wallis one-way analysis of variance. Subsequently, the differences between all possible pairs of groups were evaluated using the non-parametric Tukey-type multiple comparisons test with ranked sums (Zar 1999).

\section{Results and discussion}

Fear level, or more precisely stress level, is an important indicator of birds' welfare in commercial breeding. TI durations as a measure of fear can be influenced by the habitat in which birds live (Bilčik et al. 1998). Monitoring fear levels in our study was a part of the evaluation of the welfare of pheasants kept in various housing systems. Table 1 shows the mean duration of tonic immobility and the number of attempts to induce $\mathrm{TI}$ in common pheasant hens housed in different housing systems during laying period. 
Table 1

Mean $( \pm$ SEM) duration of tonic immobility and number of attempts to induce tonic immobility in common pheasant hens housed in conventional cages (hens treated by beak-trimming or spectacles) and in enriched cages (no beak treatment in hens) during laying period

\begin{tabular}{lccc}
\hline $\begin{array}{l}\text { Treatment } \\
\text { (Housing system) }\end{array}$ & Number of birds, $n$ & \multicolumn{2}{c}{ Tonic Immobility } \\
\hline Beak-trimming, conventional cages & 15 & $244.80 \pm 31.59^{\mathrm{a}}$ & Attempts of Induction \\
Spectacles, conventional cages & 15 & $361.63 \pm 40.61^{\mathrm{a}}$ & $1.40 \pm 0.16^{\mathrm{a}}$ \\
Intact beak, enriched cages & 15 & $111.40 \pm 21.41^{\mathrm{b}}$ & $1.00 \pm 0.00^{\mathrm{a}}$ \\
\hline
\end{tabular}

Means within a column lacking a common letter of superscript, ${ }^{a, b}$ differ significantly $(P<0.05)$.

It follows from the table that the longest duration of $\mathrm{TI}(361.63 \pm 40.61 \mathrm{~s})$ was found in pheasant hens fitted with spectacles as a protection against feather pecking and kept in conventional

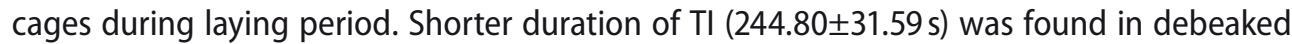
pheasant hens. However, there was no statistically significant difference between debeaked hens and hens fitted with spectacles. The shortest mean duration of tonic immobility $(111.40 \pm 21.41 \mathrm{~s})$ was seen in pheasant hens housed in enriched cages during laying period. The duration of $\mathrm{Tl}$ in hens housed in enriched cages was statistically significantly shorter in comparison with hens housed in conventional cages. No statistically significant differences were found in the number of attempts to induce TI between groups of hens housed in different housing systems.

The relationship between housing systems and fear reaction was investigated particularly in laying hens. Bilčik et al. (1998) suggest that, although the ultimate function of TI is to reduce predation, the social environment is a proximate factor affecting TI duration in domestic hens. The duration of TI is usually longer in hens housed in cages than in hens kept on a deep litter system, which can be interpreted as higher level of fear in caged hens and, therefore, lower welfare of poultry in cage systems (e.g. Jones \& Faure 1981, Kujiyat et al. 1983, Hansen et al. 1993 and others). Accordingly, Boissy (1995) states that chronically stressed animals have prolonged duration of TI. Given that nowadays a substantial number of pheasants in the breeding season is housed in cage systems in many countries (Zapletal et al. 2010), it is increasingly important to ensure the welfare of caged pheasants. Campo \& Prieto (2009) suggest that the well-being of birds can be improved with perches. Correspondingly, the use of perches (Swan 1983) has been suggested as potential management prescriptions for reducing the levels of feather pecking in pheasant pens. In our experiment, pheasant hens kept in enriched cages where perches were available during laying period showed a shorter duration of $\mathrm{TI}$ than hens kept in conventional cages. Environmental enrichment in our experimentally enriched cages included also the presence of a simple hideout in each cage. Deeming et al. (2011) investigated the effects of providing sight barriers in breeding pens on pheasant mortality, feather damage and behaviour. The authors suggest that barriers may improve pheasant welfare by reducing potentially harmful aggressive interactions, without affecting activity patterns or reproductive behaviour. According to our results, the presence of perches and hideouts may be associated with the well-being or fear levels of pheasant hens, as indicated by the TI duration. It may be concluded from our research that pheasants kept in conventional cages which exhibited longer duration of TI were more stressed and fearful than pheasants kept in enriched cages during the laying period. 
However, common means of cage enrichment to increase the welfare of pheasants breeding in captivity and to make better use of their natural behaviour, thereby decreasing the likelihood of undesirable behaviour, is unfortunately not a widespread practice. Instead of cage enrichment, beak cauterisation and various types of bits applied to the pheasants' beaks are used to prevent the pheasants from injuring one another (Fehlberg et al. 1993, Kjaer 1997). Despite its widespread use, the effect of bits and spectacles on the welfare of pheasants has received little attention. Butler \& Davis (2010) found bits to be an effective way to prevent problems caused by feather pecking and cannibalism. They did, however, cause inflammation of the nostrils and crossed mandibles in some birds. Birds fitted with bits were observed shaking and scratching their heads more than non-bitted pheasants, particularly during the first weeks. Also Swarbrick (1985) suggested that bits applied to the beak might cause welfare issues, including increased mortality. The disadvantages of beak trimming include short-term and perhaps long-term pain, and short-term stress following beak trimming (Hester \& Shea-Moore 2003). Thus, beak trimming itself and the use of bits, despite their widespread use, can be seen as the cause of significant stress in pheasants. In our experiment, no difference was found between debeaked hens and hens fitted with spectacles in TI duration at the end of the laying period, suggesting that both methods induce a similar level of fear. The painful experience of beak trimming did not disappear and once debeaked hens showed the same level of fear at the end of the laying period as hens wearing spectacles for the entire laying period. No matter what anti-pecking measure was taken the duration of $\mathrm{TI}$ in pheasant hens housed in conventional cages was significantly longer than that of hens equipped with enriched cages.

In conclusion, our results show that relatively easy and inexpensive enrichment of the cage environment (two perches, a simple hideout) where breeding groups of common pheasants are housed during laying period can significantly contribute to reduced stress/fear levels and increased welfare of pheasants kept in captivity.

\section{Acknowledgements}

This study was supported by the Research Project No MSM6215712402 Veterinary Aspects of Food Safety and Quality.

\section{References}

Anonymous (2012) Effect of spectacles on pheasants. http://www.gwct.org.uk/research__surveys/diseases__ welfare/1663.asp. [last accessed 13.01.2012]

Benoff FH, Siegel PB (1976) Genetic analysis of tonic immobility in young Japanese quail (Coturnix coturnix japonica). Anim Learn Behav 4, 160-162

Bilčik B, Keeling LJ, Newberry RC (1998) Effect of group size on tonic immobility in laying hens. Behav Processes 43, 53-59

Boissy A (1995) Fear and fearfulness in animals. Q Rev Biol 70, 165-191

Butler DA, Davis C (2010) Effects of plastic bits on the condition and behaviour of captive-reared pheasants. Vet Rec 166, 398-401

Cain JR, Weber JM, Lockamy TA, Creger CR (1984) Grower diets and bird density effects on growth and cannibalism in ring-necked pheasants. Poult Sci 63, 450-457 
Campo JL, Prieto MT (2009) Effects of moist litter, perches, and droppings pit on fluctuating asymmetry, tonic immobility duration, and heterophil-to-lymphocyte ratio of laying hens. Poult Sci 88, 708-713

Deeming DC, Hodges HR, Cooper JJ (2011) Effect of sight barriers in pens of breeding ring-necked pheasants (Phasianus colchicus): I. Behaviour and welfare. Br Poult Sci 52, 403-414

Draycott RAH, Pock K, Carroll JP (2002) Sustainable management of a wild pheasant population in Austria. Z Jagdwiss 48, 346-353

Draycott RAH, Woodburn MIA, Carroll JP, Sage RB (2005) Effects of spring supplementary feeding on population density and breeding success of released pheasants Phasianus colchicus in Britain. Wildl Biol $11,177-182$

Duncan ET, Appleby MC, Hughes BO (1992) Effect of perches in laying cages on welfare and production of hens. Br Poult Sci 33, 25-35

Fehlberg U, Sodeikat G, Schulze J, Pohlmeyer K (1993) Comparative study of commercial rearing methods of common pheasants (Phasianus colchicus) considering aspects of animal protection in extensive and intensive animal keeping. Dtsch Tierarztl Wochenschr 100, 446-449

Gallup GG Jr (1977) Tonic immobility: the role of fear and predation. Psychol Rec 27, 41-61

Gallup GG Jr (1979) Tonic immobility as a measure of fear in domestic fowl. Anim Behav 27, 316-317

Hansen I, Braastad BO, Storbraten J, Tofastrud M (1993) Differences in fearfulness indicated by tonic immobility between laying hens in aviaries and in cages. Anim Welf 2, 105-112

Hester PY, Shea-Moore M (2003) Beak trimming egg-laying strains of chickens. Worlds Poult Sci J 59, 458-474

Jendral MJ, Feddes JJR, Church JS (2005) Enriched housing environments for layer hens. Behaviour and production. Proceedings of the 7th International Livestock Environment Symposium, Bejing, China, 636-643

Jones RB (1986a) Tonic immobility in the domestic fowl: a descriptive profile. Appl Anim Behav Sci 15, 182

Jones RB (1986b) The tonic immobility reaction of the domestic fowl: a review. Worlds Poult Sci J 42, 82-96

Jones RB (1987) Assessment of fear in adult laying hens: correlational analysis of methods and measures. Br Poult Sci 28, 319-326

Jones B (1990) Is the experimenter an influential variable in studies of tonic immobility in the domestic fowl? Biol Behav 15, 93-103

Jones RB (1992) The nature of handling immediately prior to test affects tonic immobility fear reactions in laying hens and broilers. Appl Anim Behav Sci 34, 247-254

Jones RB, Faure JM (1981) Tonic immobility (»righting time«) in laying hens housed in cages and pens. Appl Anim Ethol 7, 369-372

Jones RB, Mills AD (1983) Estimation of fear in two lines of the domestic chick: correlations between various methods. Behav Processes 8, 243-253

Jones RB, Mills AD, Faure JM (1991) Genetic and experiential manipulation of fear-related behavior in Japanese quail chicks (Coturnix coturnix japonica). J Comp Psychol 105, 15-24

Keeling LJ, Gonyou HW (2001) Social behaviour in farm animals. Wallingford, UK

Kjaer JB (1997) Management practices and housing in commercial rearing of game birds in Denmark a questionnaire with focus on measurements against feather pecking and cannibalism. Proc. 5th European Symposium on Poultry Welfare. Wageningen, NL, 155-156

Kjaer JB (2004) Effects of stocking density and group size on the condition of the skin and feathers of pheasant chicks. Vet Rec 154, 556-558

Kokoszyński D, Bernacki Z, Cisowska A (2011) Growth and development of young game pheasants (Phasianus colchicus). Arch Tierz 54, 83-92

Kujiyat SK, Craig JV, Dayton AD (1983) Duration of tonic immobility affected by housing environment in White Leghorn hens. Poult Sci 62, 2280-2282

Kuźniacka J, Adamski M (2010) Growth rate of body weight and measurements in pheasants reared up to the 24th week of life. Arch Tierz 53, 360-367 
Mills AD, Faure JM (1986) The estimation of fear in domestic quail: correlations between various methods and measures. Biol Behav 11, 235-243

Olsson IAS, Keeling LJ (2002) The push-door for measuring motivation in hens: Laying hens are motivated to perch at night. Anim Welf 11, 11-19

Pavlik A, Jezova D, Zapletal D, Bakos J, Jelinek P (2008) Impact of housing technology on blood plasma corticosterone levels on laying hens. Acta Vet Hung 56, 515-527

Pohle K, Cheng HW (2009) Comparative effects of furnished and battery cages on egg production and physiological parameters in White Leghorn hens. Poult Sci 88, 2042-2051

Swan M (1983) Perches to limit feather-picking. Annu Rev Game Conserv 14, 99-100

Swarbrick $O$ (1985) Pheasant rearing: associated husbandry and disease problems. Vet Rec 116, 610-617

Tactacan GB, Guenter W, Lewis NJ, Rodriguez-Lecompte JC, House JD (2009) Performance and welfare of laying hens in conventional and enriched cages. Poult Sci 88, 698-707

Zapletal D, Suchý P, Straková E, Vitula F, Kuchtík J (2010) Behaviour patterns of the cage-housed breeding flock of pheasants (Phasianus colchicus). Acta Universitatis Agriculturae et Silviculturae Mendelianae Brunensis LIX, 215-220

Zar JH (1999) Biostatistical Analysis. 4. ed., Englewood Cliffs, New Jersey, Prentice Hall, USA

Received 23 January 2012, accepted 25 May 2012.

Corresponding author:

Petra Hrabcakova

email: petra.hrabcakova@gmail.com

Department of Veterinary Public Health and Toxicology, Faculty of Veterinary Hygiene and Ecology, University of Veterinary and Pharmaceutical Sciences Brno, Czech Republic 